\section{$\checkmark$ Medical Ethics Resource Network of Michigan: Development of a Statewide Ethics Network}

\author{
HOWARD BRODY \\ LEONARD WEBER \\ LEONARD FLECK
}

The Medical Ethics Resource Network (MERN) of Michigan has, over approximately 5 years, become a viable organization for disseminating educational information and raising the general standard of ethics discussion in a variety of institutional settings. This article reviews the history of the network's development, with special emphasis upon features that may suggest useful strategies for other networks now under formation.

\section{Origins}

To a large extent, MERN owes its origins to Gay Freeman, M.D. While a medical student at Michigan State University, Freeman participated actively in the available programs in medical ethics and played an instrumental role in revising the medical student graduation oath. On beginning her family practice residency in Midland, Michigan, Freeman was disappointed to find a lack of ethics teaching and eventually worked to remedy the defect by bringing in Drew Hinderer, Ph.D., a philos- opher teaching at Saginaw Valley State University, as a resource person to provide formal instruction. On completing her residency, Dr. Freeman became a student health physician at Central Michigan University and there became acquainted with Dena Davis, a professor of religious studies with a strong interest in medical ethics. Freeman saw in Hinderer and Davis examples of academically qualified persons who could contribute greatly to education and dialogue around ethical issues in healthcare but who lacked the advantages of regular contact with an academic medical center. She thought that such individuals could greatly expand the teaching of ethics in community hospital settings if a mechanism could be created to link them up with nearby sites desiring their expertise.

Eventually, Freeman engineered a meeting of several faculty members from the Medical Humanities Program (later the Center for Ethics and Humanities in the Life Sciences) at Michigan State University (MSU), along with Davis and Hinderer, at her home in rural central Michigan. Over a pot of soup in her kitchen, the preliminary plans for a statewide ethics resource network first emerged.

In October 1986, an organizational meeting was held at MSU, funded by a small planning grant from the Michigan Council for the Humanities. Approximately 20 individuals were invited. The criteria for invitation were as follows: 
1) Individuals should represent a mix of professional backgrounds and geographic regions.

2) Individuals should be divided between those with primarily academic appointments and those with practical clinical involvement in community healthcare.

3) All should have an interest in medical ethics, either academic or practical.

4) Each person should have a proven track record of accomplishment in his or her local setting, having created a new course or program, begun an ethics committee, or otherwise shown the ability to carry a task to completion.

The group met for 2 days and discussed a range of possible structures, from an informal club to a formally created nonprofit organization. The group elected to pursue the more ambitious structure and created subcommittees to work on bylaws, membership recruitment, funding, and research projects.

\section{Initial Projects}

Members of the MERN Board (which had been created out of the 20 individuals invited for the planning meeting) initially approached the Michigan State Medical Society and the Michigan Hospital Association for financial support. The Medical Society responded with a small contribution and, more importantly, provided the mechanism for MERN to conduct a survey of a number of hospital ethics committees that were known to the Medical Society. The Medical Society also allowed MERN to participate in a statewide meeting of physician members of ethics committees. The survey resulted in a needs assessment that clearly identified ethics committees as a constituency interested in MERN and in need of the services of a communications network. In particular, the development of educational materials for hospital ethics committee members was identified as a high priority, and a special task force was created to begin work on a series of modules to meet this need.

Some money from the original Michigan Council for the Humanities grant remained unspent at the completion of the planning conference, and this was invested in the creation of a computer bulletin board to facilitate MERN communications. Computer expertise and facilities were obtained through the computer center at MSU. It was hoped that this would facilitate the creation of a printed newsletter, as bulletin board items could simply be printed out at intervals into the columns of the newsletter.

\section{Organizational Changes}

MERN needed an office, a secretary, and the part-time services of an executive director to become a viable organization. The initial contacts with the Michigan State Medical Society and the Michigan Hospital Association suggested that MERN might find a home under the umbrella of the Michigan Health Council. This was an interdisciplinary organization involved in activities such as community health fairs and efforts to recruit physicians to rural areas. It seemed a good home for MERN because it was interdisciplinary, served the entire state, and already received some funding support from the Medical and Hospital Associations. It was hoped that these associations might provide financial support for MERN indirectly by increasing their grants paid to the Michigan Health Council.

Initially, the planning board felt that MERN would fairly easily attract grant support. In 1986, MERN seemed a new idea. Although other states, notably Minnesota, had created networks to 
link hospital ethics committees, no state had created a network that was open to all individuals interested in medical ethics. The board hoped that the executive director of the Michigan Health Council would see MERN as a promising source for funding and would therefore put energy into fund raising and foundation contacts. Because the Michigan Health Council was already a nonprofit corporation and had tax-exempt status, it was also seen as a savings that MERN would not have to apply for its own separate credentials in those areas.

Unfortunately, experience over 1 year showed that these objectives had not been met. The director of the Michigan Health Council was too busy with other pressing activities to devote much time to MERN and had no particular interest or expertise in ethical issues as such. Moreover, when the funding for MERN did not materialize as rapidly as was hoped and MERN threatened to become a financial drain rather than an asset to the Council, the director noticeably lost interest.

Finally, the MERN board felt it necessary to sever ties with the Michigan Health Council and to seek another organizational home. The staff at MSU had felt that it would be inappropriate to locate MERN at a major university, lest the other academic centers in the state feel that a competitive turf battle was being created. However, representatives of other academic centers strongly urged the MSU Center to take on MERN as a project, and locating the MERN office at MSU created none of the hostility or suspicion that had originally been feared.

\section{Finances}

When the hoped-for large grants did not appear, the MERN board decided that MERN would have to be self-supporting through membership dues.
Dues categories were created for individual and institutional members. Individual memberships were low, covering merely the cost of mailings and services. Therefore, the organization hoped to derive most of its funding from institutional memberships, primarily hospitals.

Unfortunately, the first year that MERN solicited dues-paying memberships from hospitals was also the first year that Michigan hospitals, on average, lost money. The difficult financial straits of hospitals slowed the membership drive considerably. Therefore, it was necessary for MERN operations to be heavily subsidized, first by the Michigan Health Council, and later by the MSU Center for Ethics and Humanities. Over time, MERN board members made presentations to hospital administrators and trustees and encouraged hospital ethics committees, whose members and chairs saw the value of the MERN organization, to lobby within their institutions for membership. Through these efforts, the membership began to grow. After approximately 4 years, MERN began to generate dues roughly comparable to the cost of maintaining the organization's central office, publishing its newsletter, and producing the educational modules series.

In retrospect, it was probably to MERN's advantage that a major grant was not obtained at the inception. Being poor forced the MERN board to devote a great deal of energy to member recruitment, to look carefully at the needs of its member organizations and institutions, and to try hard to develop a "product line" that would meet the members' needs and attract additional membership. Because MERN was obviously poverty stricken, many of the board members pitched in and offered significant portions of time and energy on a volunteer basis. Thus MERN became more active earlier at the "grass roots" level than might have been the case with major grant support. 


\section{Successes After 5 Years}

In 5 years of development, MERN has achieved some major successes. It boasts 51 hospital institutional members and 125 individual members. When a special dues category was created to offer hospices and nursing homes a lower cost institutional membership, the response was immediate and positive, with 45 institutions eventually joining on that basis.

MERN has now held four annual spring meetings, each $1 \frac{1}{2}$ days, with a gradually increasing attendance (approximately 110 participants at the last meeting). The computer bulletin board remains active, and 850 copies of the newsletter, Ethics-In-Formation, are distributed six times annually. Nine modules have been created for the series on hospital ethics committee educational materials.

In other ways, MERN has been less successful than was originally anticipated. To a large extent, the computer bulletin board remains a "read only" activity; MERN members outside of the central office regularly access the bulletin board but appear quite reluctant to contribute news items and discussion material. The bulletin board has not become the lively interactive forum that was imagined.

The research component initially envisioned for MERN, notably a project to identify aspects of hospital ethics committee process and strategies to improve that process, has never been implemented. Moreover, efforts to get hospital ethics committees to be more active in self-evaluation and peer review have likewise received little response.

\section{New Initiatives: Just Caring}

Until now, hospital ethics committees have had relatively little to do with issues of rationing and resource alloca- tion or other justice-related concerns in medical ethics. However, that situation will be changing in the very near future, and it ought to. At the level of macropolicy, we will see an increasing number of healthcare cost containment policies put in place, such as DRGs. At the macro level it is virtually impossible to judge whether or not these policies are fair, all things considered, because the most important consideration is how these policies are implemented at the institutional level. That implementation will tend to be primarily a responsibility of top-level administrators. The code of ethics promulgated by the American College of Health Care Executives was radically revised in late 1987. Their original code (1973) barely deserved to be called a code of ethics because the primary focus was on the responsibility of hospital administrators to protect and advance the interests of the institution. In the revised code, justice is the moral value that holds center stage.

Cynics may wonder whether hospital administrators are aware of this revised code of ethics, and if they were even aware of the first. One of the values of MERN and its newsletter is that we were able to do a lengthy article calling attention to this revised code of ethics for the benefit of members of institutional ethics committees. There is real moral leverage in a publicly promulgated professional code of ethics. Administrators who would callously advance institutional self-interest at the expense of healthcare justice can be called to task quite effectively by a hospital ethics committee with the help of this code. That is, they are denied the opportunity to claim that some "outside party" is trying to impose "its values" on the institution when that "outside party" is their own professional organization.

One of the more interesting passages from that 1987 code says that healthcare executives should provide health ser- 
vices "consistent with available resources and assure the existence of a resource allocation process that considers ethical ramifications." Not everyone can get everything in the way of health resources from which they might benefit. Choices have to be made, and administrators will have to play a central role in the management of those choices. Specifically, they will need to create a process for making these choices fairly, something richer and more dynamic than cookbook allocation policies.

What a creative and committed administrator can do is cultivate a climate for moral conversation about these issues in the hospital as a whole. This conversation might be institutionally focused in the workings of a hospital ethics committee. But if that committee is supposed to be a self-contained policymaking/decision-making body, as the infamous dialysis selection committees were in the late 1960s, then the results will be equally embarrassing and morally problematic. Ideally, hospital ethics committees should be doing nothing more than distilling a moral conversation regarding healthcare justice that is widely disseminated throughout that institution and throughout the community served by that institution. If the need for some form of healthcare rationing is really inescapable, as we argue, then it is of preeminent moral importance that rationing protocols be recognized by the community at large to be self-imposed rather than organizationally imposed, even under the auspices of a hospital ethics committee. Therefore, there must be broad, sustained community conversations aimed at articulating a very detailed understanding of what a just and caring community should do by way of establishing health priorities in the face of real resource limits.

Generating these kinds of community conversations that must be sus- tained over a period of many years is really beyond the capacity of any single hospital administrator or institutional ethics committee, especially when the individuals who serve in these roles have numerous other pressing organizational responsibilities. This is where an organization like MERN has a critical role to play. Through MERN, we have been able to bring into existence the "Just Caring" project in Michigan. This project is aimed at creating public forums in which healthcare professionals and thoughtful citizens can engage in a sustained and systematic discussion of critical moral issues raised by changes in healthcare technology, health-care delivery, healthcare financing, and healthcare policy. Specifically, the project will take place at 20 sites throughout Michigan over a 3-year period. There will be a group of 50 individuals broadly representative of that community at each site, and they will be the focal point of a community conversation about a broad range of issues of healthcare justice for a total of 30 sessions at each site. The conversations will be focused and structured through assigned readings, case discussion, policy discussion, and a broad variety of exercises aimed at eliciting considered moral judgments about a number of problems of healthcare justice. A project of this magnitude will generate substantial media visibility, which will in turn stimulate a lot of spin-off conversations about these issues around the state that we hope will yield some significant degree of moral agreement regarding, for example, rationing protocols that would become part of the workings of each community hospital.

The "Just Caring" project itself will have only a limited life span, but it will produce the resources needed for sustaining this conversation into the indefinite future. The conversation will go on because it will become institutionally focused through individual hospital 
ethics committees, and the conversation will remain coherent because it will be coordinated through MERN. That coherence is the coherence of rationality and reasoned public debate, which is essential to protecting the stability and integrity of just policies and practices.

\section{Advantages of Networking}

Besides the successes and new initiatives summarized above, our experience has indicated several other advantages of a statewide ethics network. Because many policy and legislative issues are addressed at a state level, and because many professional groups have statewide organizations, a statewide ethics resource network has practical value as a potential cosponsor of educational programs and of projects designed to affect state policy making. As this role expands, the network will have to clarify for itself the extent to which taking a position on various policy matters is consistent with its educational and broadly representative mission. For example, MERN initially refused to take any position on policy matters other than to encourage broad discussion and debate of all viewpoints. More recently, the Board decided to add its endorsement to a Department of Public Health report on HIV-infected healthcare workers.

As a service to members of institutional ethics committees, statewide networks have the resources and the geographical identification to provide a unique educational function. For example, the annual MERN meeting combines two important characteristics: 1) it is close enough and inexpensive enough to be accessible to many committee members across Michigan, and 2) most of the conference presenters are themselves members of the network. Therefore, ethics committee members get to meet and hear ethics resource persons from within the state, who will remain available locally for later consultation and cooperation if this is desired. Contacts made at these meetings frequently lead to further educational efforts at the home institution. This would occur much less often if committee members had to fly to New York or Seattle to obtain in-depth continuing education on healthcare ethics.

MERN has successfully carried out one of Dr. Gay Freeman's initial goals, developing closer collaboration among academic ethicists and those employed fulltime in healthcare settings. These collaborations are evident in the increased use of academic ethicists as part-time resource people in hospitals and in the intensive summer week-long ethics course that MERN and MSU have cosponsored twice.

\section{Conclusion}

MERN has shown that a statewide ethics network can emerge through a combination of some leadership initiative in the larger academic centers and intensive "grass roots" activity at numerous sites around the state. Ultimately such a network can be self-sustaining even without major grant support. It can provide services that are valuable to its members. While addressing the needs of hospital and institutional ethics committees, it can also serve a broader set of interests and can appeal to all individuals in the state who have some reason to be interested in the general field of healthcare ethics. The network can also play a positive role in the creation of legislation and public policy. 